\title{
A portrait of cadmium
}

Nadezda V. Tarakina and Bart Verberck explore the colourful history and assets of element 48.

n early-nineteenth-century Prussia, quality control of pharmaceuticals was entrusted to government-appointed physicians. In 1817, one such physician, Johann Roloff, became suspicious of a batch of zinc oxide that could be traced back to the factory of Karl Hermann. Roloff's preliminary tests suggested that the samples contained arsenic, and so Hermann - worried about the reputation of his business - investigated further. He and others soon discovered that arsenic had nothing to do with it, but that an unknown metal was involved.

Meanwhile, Friedrich Stromeyer, Inspector-General of the apothecaries in the neighbouring Kingdom of Hanover and professor at the University of Göttingen, was investigating some puzzling zinc carbonate samples that, upon heating, left behind a yellow oxide. He managed to isolate the source of the yellowness down to the oxide of a new metal.

The entangled roles of Roloff, Hermann and Stromeyer - who corresponded and wrote about their findings - make it virtually impossible to give someone sole credit for the identification of the new element ${ }^{1}$. Furthermore, others also published reports on the discovery. Different names for the element were suggested, including klaprothium, in memory of the chemist (and elementdiscoverer) Martin Klaproth, and melinum, from the Latin melinus: referring to the colour of a quince. However, the name cadmium originally proposed by Stromeyer — stuck. His proposal came from the root cadmia: Latin for calamine, which is an umbrella term referring to various zinc-based minerals.

Cadmium partners vividly with sulfur: $\mathrm{CdS}$ is a yellow solid - hence the suggestion of melinum - and has long been a fixture on painters' and graphical artists' colour palettes under the name 'cadmium yellow'. Solid solutions with selenium (cadmium sulfoselenides) serve as pigments covering orange to red; mixing $\mathrm{CdS}$ with $\mathrm{ZnS}$ produces a yellow-green tone. As such, cadmium pigments have been embraced by artists since

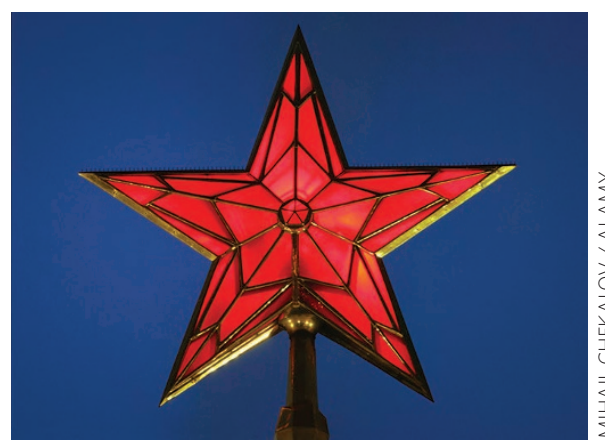

the nineteenth century. They are known for their outstanding hiding power, light-fastness and stability - qualities that also make them excellent industrial paints. Indeed, thanks to their resistance to temperatures up to $3,000{ }^{\circ} \mathrm{C}$, cadmium pigments can be used for painting hot pipes or glass - for example in red traffic lights or the lit stars on the Moscow Kremlin (pictured).

The physical reason for this plethora of colours is that these II-VI cadmium compounds are semiconductors with a bandgap in the visible spectrum. CdS has a bandgap of $2.42 \mathrm{eV}(512 \mathrm{~nm})$ and therefore absorbs blue, indigo and violet: the spectral complement is thus perceived by the human eye as yellow.

$\mathrm{CdS}$ and CdSe nanoparticles are popular quantum dots. On the nanoscale, due to quantum confinement effects, the absorption threshold of semiconductors becomes size dependent: the smaller the dot, the higher (bluer) the energy threshold. The size of such nanoparticles therefore provides a handle for tuning their optical properties, handy for use in display screens - modern pigments, if you like.

Cadmium has no known biological function in higher organisms. In fact, it is highly toxic and regulations on its use have become increasingly stringent - cadmium salts are gradually being replaced by azo compounds in commercial paints.

Because of its ability to capture neutrons, cadmium played an instrumental role in the development of the very first nuclear reactor - cadmium-coated rods were being used to control the nuclear reaction ${ }^{2}$.
From 1907 to 1960, cadmium moonlighted as a metrology standard. During that time, the ångström was defined by fixing the wavelength of a distinct, red spectral line of cadmium at $6438.4696 \AA$ - a choice put forward by physicist Albert Michelson ${ }^{3}$. In 1960, the ångström became coupled to the metre, and the latter was redefined in terms of a particular spectral wavelength of ${ }^{86} \mathrm{Kr}$.

But cadmium is perhaps best known for its use in battery technology. The invention of the rechargeable nickel-cadmium battery goes back to 1899 , and has played a major role in electrical technology throughout the twentieth century. A cell built from cadmium and $\mathrm{NiO}(\mathrm{OH})$ electrodes delivers a potential of 1.2 volt; $\mathrm{Ni}-\mathrm{Cd}$ batteries have superb characteristics, including robustness, stability and long life. However, because of cadmium's toxicity, the use of $\mathrm{Ni}-\mathrm{Cd}$ batteries has been progressively banned in recent years, for example by the European Union's Battery Directive $^{4}$, encouraging adoption of less hazardous alternatives such as nickel-metal hydride and lithium-ion batteries.

According to Greek mythology, Cadmus brought the (Phoenician) alphabet to Hellas. Over the past 200 years, cadmium has also brought us plenty. Its toxic nature has somewhat caught up with it colourful past, seeing it replaced here and there. But when handled with care, the element's unique merits in chemistry's alphabet can still be put to good use.

NADEZDA V. TARAKINA is in the School of Engineering and Materials Sciences, Queen Mary University of London, Mile End Road, London E1 4NS, UK. e-mail:n.tarakina@qmul.ac.uk

\section{BART VERBERCK is a Senior Editor at Nature Physics.}

\footnotetext{
References

1. Fontani, M., Costa, M. \& Orna, M. V. The Lost Elements: The Periodic Table's Shadow Side (Oxford Univ. Press, 2014). 2. December 2, 1942: first self-sustained nuclear chain reaction. APS NEWS (December 2011); http://go.nature.com/2gxDxYt

3. Jackson, C. V. Proc. R. Soc. Lond. A 155, 407-419 (1936).

4. Directive 2006/66/EC of the European Parliament and of the Council (European Union, 2006); http://ec.europa.eu/ environment/waste/batteries/
} 